\title{
Planeta ROODA: inovações no AVA a partir de propostas pedagógicas para o ensino fundamental
}

\author{
Caroline Bohrer do Amaral, UFRGS, carol.bba@ gmail.com Anna \\ Helena Silveira Sonego, UFRGS, sonego.anna@gmail.com \\ Patricia Alejandra Behar, UFRGS, pbehar@terra.com.br \\ Maria Luiza R. Becker, UFRGS, mlbecker@portoweb.com.br \\ Ana Luísa Fonseca, UFRGS, aclfonseca1@gmail.com Bruna \\ Kin Slodkowski, UFRGS, brunakinnuted@gmail.com \\ Larissa Camargo Justin, UFRGS, larissacjustin@gmail.com \\ Lucas Souza da Rosa, UFRGS, lucas-souza34@hotmail.com
}

\begin{abstract}
Resumo
Este artigo trata de um ambiente virtual de aprendizagem (AVA), Planeta ROODA, voltado à educação escolar. $\mathrm{O}$ objetivo é investigar como professores do ensino fundamental elaboram propostas pedagógicas para o AVA considerando-se princípios teóricos interacionistas como as trocas sociais, o interesse e a atividade do estudante. Um levantamento de artigos demonstrou haver um número escasso de produções científicas envolvendo AVA e ensino fundamental. A metodologia de pesquisa é estudo de caso. Os dados constituem-se de entrevistas com professores e registros de atividades realizadas em um curso de extensão. Como resultados, constata-se, com os cursos, que as funcionalidades do Planeta ROODA podem potencializar a construção de propostas pedagógicas interacionistas. Como exemplo, consideram-se a troca de ideias, o compartilhamento de produções assim como a autoria de textos, desenhos, vídeos e projetos. As entrevistas mostraram que a estrutura tecnológica de escolas públicas é precária, especialmente quanto à disponibilização de internet. Por outro lado, o celular está presente no cotidiano dos estudantes e alguns professores os utilizam em suas práticas. Tal fato corroborou para o desenvolvimento da terceira versão do Planeta ROODA, a qual contará com uma versão para dispositivos móveis.
\end{abstract}

Palavras-chave: Propostas Pedagógicas; Ensino Fundamental; Ambiente Virtual de Aprendizagem.

\section{Planet ROODA: innovations in the VLE from pedagogical proposals for Elementary Education}

\begin{abstract}
This article deals of a virtual learning enviroment (VLE), ROODA Planet, in order to schooling. The objective is to investigate how elementary school teachers elaborate proposals to the VLE considering the interactionist theoretical principles as socials exchanges, the interest and the student activity. An analysis of articles on the subject demonstrate a small number of scientific productions involving the study of VLE in elementary schools. The research methodology is a case study. The datas made up of interviews with teachers and activity logs an extension course with the VLE. As a result, as seen during the extension course, the features of ROODA Planet can increase the construction of interactionist pedagogical proposals. As example, considering sharing of ideias, sharing posts like written texts, drawings, videos and projects. The interviews show that the technological structure of public schools is poor, especially the availability of the internet. On the other hand, the smartphones are widely present in the daily lives of students and teachers, who use in their activities. This fact corroborated
\end{abstract}


for the development of the third version of ROODA Planet, which will feature a mobile version.

Key words: Pedagogic proposals; Virtual Learning Environment; Elementary School.

\section{Introdução}

Os ambientes virtuais de aprendizagem (AVA) são amplamente utilizados na Educação a Distância, pois reúnem diferentes ferramentas que facilitam a organização de recursos pedagógicos e a interação entre os atores educacionais. No entanto, o seu uso em instituições escolares ainda não é recorrente. Os AVA vigentes atendem o público adulto, especialmente aqueles de filosofia livre, como o Moodle, por exemplo. É incomum encontrar versões desses ambientes voltadas às escolas, com as devidas adaptações de linguagem e design gráfico.

A despeito da rapidez como as tecnologias digitais se disseminam na sociedade, as escolas apropriam-se gradativamente de seus benefícios. A precária infraestrutura tecnológica existente em algumas escolas públicas e a qualidade das formações de professores nesta área são pontos críticos que implicam no aproveitamento limitado das tecnologias digitais pelas instituições escolares. As pesquisas realizadas periodicamente pelo Centro Regional de Estudos para o Desenvolvimento da Sociedade da Informação (CETIC.br) em escolas públicas e privadas de educação básica contribuem para o entendimento da realidade escolar brasileira no que tange à informatização. Um dos dados mais relevantes trata da conexão à Internet sem fio em escolas públicas. Apesar de $67 \%$ afirmarem possuir acesso, a maior parte de diretores informa que a baixa velocidade de conexão é fator restritivo para seu uso. Quanto a este dado, observa-se que locais administrativos, como sala do coordenador ou diretor, e a sala dos professores, são predominantes entre os locais cobertos pela rede sem fio, o que mostra uma limitação quanto acesso pelos estudantes (CENTRO..., 2015). Ademais, a maioria dos diretores de escolas admite que a senha da internet banda larga não é disponibilizada para os estudantes.

Outro aspecto interessante da pesquisa está relacionado à abordagem pedagógica pelos professores que utilizam os recursos. Ao investigar o foco de práticas pedagógicas envolvendo tecnologias digitais, a pesquisa aponta que, em 2010 , quase $70 \%$ do ensino voltava-se a como usar essas tecnologias (CENTRO..., 2015). Quanto a essa questão, no levantamento realizado em 2014, a proporção ainda é a mesma. Em contrapartida, a expectativa é que as tecnologias se constituam como meio para estabelecer relações de ensino e aprendizagem nos diferentes componentes curriculares, conforme orientam as Diretrizes Curriculares Nacionais Gerais para a Educação Básica (BRASIL, 2010). Ao analisar dados da pesquisa TIC Educação 2015, Almeida (2015, p. 51) afirma "a necessidade de outras políticas para a formação continuada de professores para uso pedagógico das TIC e empenho para iniciativas de formação inicial". Logo, entende-se como imprescindível que pesquisadores e profissionais da educação se debrucem sobre diversas questões que envolvem a implantação das tecnologias digitais na escola.

Nesse contexto, o presente artigo trata sobre propostas pedagógicas para um ambiente virtual de aprendizagem (AVA) chamado Planeta ROODA ${ }^{1}$. Este ambiente foi construído por um grupo de pesquisa com a finalidade de apoiar o processo de ensino e aprendizagem em escolas. Sua estrutura possibilita práticas pedagógicas autorais, coletivas e interdisciplinares no ensino fundamental. Dessa maneira, a pesquisa tem como objetivo investigar como professores criam propostas pedagógicas para o Planeta ROODA, considerando-se o potencial para trocas sociais, interesse e atividade do 
estudante. Os pressupostos interacionistas (PIAGET, 1998; MACEDO, 2005) constituem o referencial teórico e orientam a análise.

A fim de conhecer o cenário em que se situa este estudo, realizou-se um levantamento de trabalhos correlatos em duas bases de dados, foco da próxima seção. Este artigo está organizado em sete seções. Além do referido levantamento, as seções seguintes versam sobre tecnologias digitais, construção do Planeta ROODA, planejamento sob o ponto de vista interacionista, metodologia da pesquisa, discussão e resultados obtidos a partir das propostas pedagógicas de professores para o AVA e, por fim, na última seção, encontram-se as considerações finais.

\section{Levantamento de trabalhos correlatos}

Para conhecer o contexto científico em que se situa o estudo, realizou-se um levantamento de artigos em duas bases nacionais: a Revista Novas Tecnologias na Educação (RENOTE) e o Portal de Periódicos da CAPES. A primeira por se relacionar especificamente a uma revista científica na área de tecnologias e educação e a segunda pela sua abrangência e caráter científico. As buscas, por sua vez, foram efetuadas sem restrições em relação a datas e a partir dos seguintes descritores: "ambientes virtuais de aprendizagem" e "ensino fundamental".

Na RENOTE, valendo-se dos referidos descritores, foram encontrados apenas seis artigos, porém estes não continham o foco no ensino fundamental, conforme informações de seus resumos e palavras-chave. Apesar disso, optou-se por analisar os artigos resultantes da busca. Estes foram considerados relevantes no âmbito educacional, visto que os professores exploraram as ferramentas dos ambientes virtuais em suas práticas pedagógicas a fím de construir conhecimentos. Além disso, alguns textos apontam como resultados a interação do aluno com o ambiente virtual, o desenvolvimento da autonomia e também a curiosidade, os quais foram motivados através da pesquisa na web referentes a temas de seus interesses ${ }^{2}$ (ZIEGLER et al., 2014; COSTA e FRANCO, 2005). Já da pesquisa conferida no Portal de periódicos da CAPES, obtiveram-se cinco artigos, sendo que um foi descartado da análise por não possuir o ensino fundamental como foco. Foi constatado por intermédio das análises dos artigos da CAPES que apenas dois mencionaram que os AVA eram de suas autorias (ZIEGLER et al., 2014; BRENNAND e BORGES, 2010). A interatividade é citada como fundamental pelos autores para práticas educativas em AVA, assim como a criação de ferramentas adequadas ao público-alvo para a aprendizagem colaborativa (PASSERINO et al., 2007; RIGO, 2013; COSTA e FRANCO, 2005).

Considerando o potencial das tecnologias para a educação e, em especial, os AVA, observou-se, a partir desse levantamento, números pouco significativos de artigos voltados ao tema e um número ainda menor em relação àqueles que tratavam de seu uso no EF. Comparando dados dos trabalhos encontrados aos princípios que embasam o Planeta ROODA, destacam-se a relevância de as ferramentas dos AVA possibilitarem a interação entre os participantes, a curiosidade, a participação do estudante, as trocas sociais, a autonomia, a criatividade e a autoria.

\section{Tecnologias digitais na educação escolar: possibilidades a partir do AVA Planeta ROODA}

As tecnologias digitais se constituem como meio para o estabelecimento de relações de ensino e aprendizagem em práticas virtuais, podendo atravessar os diferentes componentes curriculares. Isso significa que a instrumentalização digital, ou seja, a 
preparação para o uso das tecnologias apesar de necessária, não precisa ser a única abordagem nas escolas. As práticas em que os estudantes são ativos propiciam que eles aprendam a selecionar conteúdo de forma crítica, a estabelecer relações coerentes entre as informações, a produzir seus próprios materiais e a compartilhá-los. Com base nos pressupostos piagetianos (PIAGET, 1998), o professor pode desafiar a compreensão inicial dos estudantes com questionamentos, com outros materiais e outros pontos de vista, sendo desde a opinião dos próprios colegas até os conteúdos científicos. Assim, é importante que os professores conheçam as ferramentas e tenham fundamentação teórica suficiente para utilizá-las de forma crítica.

Neste estudo, parte-se da premissa que os ambientes virtuais de aprendizagem são tecnologias digitais que favorecem a realização de práticas virtuais fundamentadas em princípios interacionistas, ou seja, que valorizam a interação e a construção do conhecimento. Segundo Behar et al. (2013), os AVA permitem a organização de cursos e disciplinas, a administração de conteúdos de estudo e o monitoramento de alunos nas modalidades presencial, semipresencial e a distância. Dessa maneira, um AVA também pode ser utilizado no ensino presencial em escolas.

O AVA do qual se trata nesta pesquisa é o Planeta ROODA. Este ambiente é desenvolvido por uma equipe multidisciplinar formada por pedagogas, programadores e webdesigners vinculados ao Núcleo de Tecnologia Digital Aplicada à Educação (NUTED) da Universidade Federal do Rio Grande do Sul (UFRGS) e coordenado pela Prof $^{a}$. Dr ${ }^{a}$. Patricia Alejandra Behar. Teve sua primeira versão em 2006 e, desde lá, caracteriza-se como um software livre. A temática de espaço sideral inspirou todas as suas diferentes interfaces. Sua concepção está amparada na perspectiva interacionista. Assim, suas funcionalidades possuem potencial para subsidiar a construção de conhecimentos, o compartilhamento e as trocas sociais.

O ambiente está na terceira versão, a qual tem o objetivo de renovar a tecnologia de sustentação, o design de interface, assim como realizar melhorias na estrutura pedagógica das funcionalidades, buscando atender os interesses do atual público escolar. O curso de extensão, a ser detalhado nas próximas seções, capacitou professores para utilização da segunda versão do AVA. Dessa experiência, surgiram demandas que corroboraram a elaboração da última versão, a 3.0, como por exemplo, a sua disponibilização compatível com dispositivos móveis (tablets e smartphones). Uma das dificuldades apontadas pelos professores é a indisponibilidade de laboratórios de informática e, especialmente, a falta de acesso à internet em suas escolas. Com o incremento da versão Mobile, professores e estudantes obterão acesso rápido e portátil, diferenciando-se da versão do Planeta ROODA 2.0. Além disso, surgiram novas necessidades referentes à estrutura interna do ambiente, layout mais atualizado e à possibilidade de um sistema capaz de registrar os passos do usuário para geração de relatórios.

Para tanto, a ferramenta está sendo desenvolvida na parte de back-end utilizando linguagem PHP e front-end Javascript e HTML com Kube CSS framework. O banco de dados está implementado em SQL e é gerenciado através da ferramenta phpMyAdmin. A linguagem escolhida, PHP, fornece suporte integrado ao banco de dados, além de ser independente do navegador utilizado pelo usuário. O PHP conta com uma grande base de usuários, que disponibilizam bibliotecas de software livre que tornam a aplicação mais eficiente e segura, entre as quais utilizou-se: MySQLi-DB, que proporciona níveis de segurança com os dados armazenados no banco destinado a esse fim; PHPMailer, que permite que o Planeta ROODA 3.0 envie e-mails de confirmação de cadastro, recuperação de senha; PHPOffice para efetuar cadastro de usuários através de planilhas Excel; HTMLPurifier a fim de evitar qualquer entrada de dados pelo usuário que possa 
conter códigos maliciosos que afetem a aplicação. No que se refere à interface, as definições e a implementação foram realizadas pelo responsável do design, a partir da linguagem HTML e Javascript (desenvolvimento front-end). Esta se difere do back-end quanto à sua implementação em navegadores, o qual permite que o usuário manipule a navegação de forma assíncrona com o sistema.

$\mathrm{Na}$ esta última versão, existem cinco níveis de usuários, os quais se diferem por suas permissões dentro do ambiente, são eles: Coordenador, Professor Responsável, Professor, Monitor e Aluno. Estes níveis foram criados pensando em atender as necessidades das escolas. Atualmente, o Planeta ROODA 3.0 conta com as seguintes funcionalidades: Aulas, Atividades, Minha Página, Página da Turma e Projetos, conforme mostra a Figura 1. Cada funcionalidade é representada por um domo. A estrutura do AVA é aberta, ou seja, o professor configura as funcionalidades de acordo com a sua metodologia.

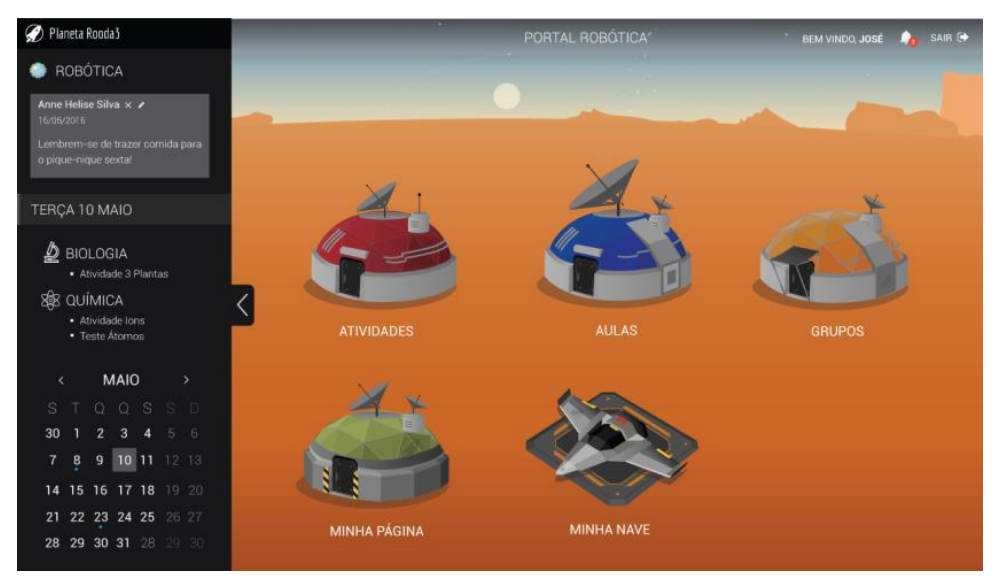

Figura 1 - Tela: funcionalidades

A primeira, Aulas, permite a publicação de postagens pelo professor através de um editor de texto HTML, conforme exibido na Figura 2. Este viabiliza a inserção de textos e imagens e a incorporação de vídeos e links publicados em outros sites. Também se pode anexar arquivos de diferentes extensões.

Cada aula pode ser relacionada a uma área de conhecimento disponível no sistema ou personalizada pelo professor. A funcionalidade Atividades destina-se à criação de questionários a partir de questões descritivas, múltipla escolha ou verdadeiro e falso, como ilustrado na Figura 2. O professor tem a possibilidade de personalizar o sistema de notas para cada questionário e, nas permissões, pode habilitar que monitores e estudantes também criem atividades. Minha Página é um espaço único para cada participante realizar suas

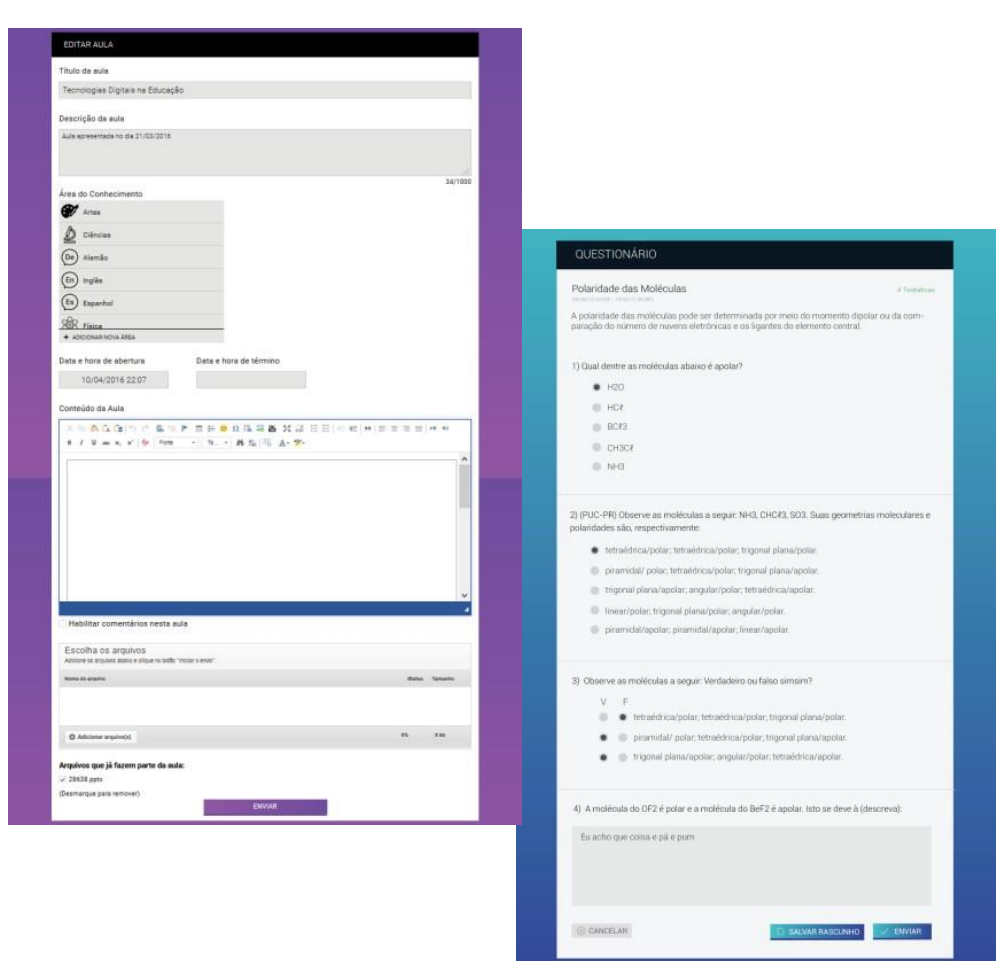

Figura 2 - Tela: criar Aula
Figura 3 - Tela: Atividades 
postagens em um editor HTML idêntico ao da funcionalidade Aulas. Do mesmo modo, pode-se incluir arquivos e destinar a postagem para uma área de conhecimento. Em Página da Turma, é possível acompanhar as postagens de colegas bem como realizar comentários, tendo sua estrutura próxima a de redes sociais. A última funcionalidade desenvolvida até este momento é Projetos, constituindo-se de um espaço para criação individual ou coletiva (grupos) de postagens. Todos os membros de um projeto podem editar as postagens e acompanhar as diferentes versões.

Para desenvolver a nova interface do AVA, foi necessário definir o público-alvo, levantando-se requisitos de usuário. Por se tratar de um público infanto-juvenil, construiu-se uma interface intuitiva e atrativa. Com base em suas necessidades, na análise das versões anteriores do ambiente e no aspecto pedagógico, foram criados o padrão de projeto e a estrutura do site. Segundo estudos de movimento de olhos e leitura de página, como a de Nielsen (2009), a interface foi dividida em 3 seções para facilitar a interpretação. Seguiu-se a teoria da leitura em F: o cabeçalho, a barra lateral e o conteúdo principal no centro. Quanto ao padrão projetual, implementou-se a fonte Roboto de Christian Robertson por possuir uma variedade ampla de pesos e por ser Open Source. Os componentes do AVA como ícones e botões seguem o modelo flat que contribui para se obter uma interface simples e de fácil compreensão. As características claras desses componentes conciliam os elementos mais complexos como os domos, planetas e fundos que possuem diversos detalhes e seguem um estilo mais realístico. A próxima seção aborda os aspectos pedagógicos relacionados à pesquisa com o AVA.

\section{Planejamento: perspectiva interacionista}

Para subsidiar a análise de propostas pedagógicas para o Planeta, é utilizada a perspectiva do planejamento na educação, a partir de princípios interacionistas. $\mathrm{O}$ planejamento constitui uma das etapas do fazer pedagógico e através dele é possível observar alguns aspectos da prática docente tais como, a escolha dos conteúdos, das atividades, dos materiais didáticos, da metodologia de trabalho, das estratégias pedagógicas e da avaliação. Nesta perspectiva, Macedo (2005) defende a ideia de o planejamento ser uma etapa relevante para a composição das práticas pedagógicas.

Logo, considera-se o planejamento como uma construção, na qual a antecipação é uma importante forma de regular a prática. Antecipar é comprometer-se com aquilo que se quer que algo se torne (MACEDO, 2005). Nesta relação, o autor estabelece, sublinha a importância de o docente partir dos conhecimentos prévios e interesses dos estudantes para criar formas de alcançar seus objetivos. Logo, é preciso (re)conhecer o público e o seu contexto. Dessa maneira, os planejamentos não são estanques, mas sim, retroalimentados pelas práticas e demandas dos estudantes.

O processo de construção do planejar em direção ao trabalho mais consciente, intencional e produtivo passa pela reflexão do professor, com subsídio de teorias educacionais. Acredita-se que quando professor reflete, pode realizar escolhas cada vez mais intencionais. De acordo com a explicação de Piaget (1977), a reflexão potencializa o avanço em outros patamares da tomada de consciência. Isso porque o processo de abstração refletida permite que a conceituação ultrapasse o nível da ação atingindo a compreensão, possibilitando a antecipação e o planejamento de ações. A análise reflexiva sobre as ações pedagógicas pode ser mais coerente e profunda considerando-se pressupostos teóricos. Desse modo, a formação continuada de professores pode ser uma forma de contribuir para a renovação de suas práticas. 


\section{Metodologia}

A análise de propostas pedagógicas, apresentada na discussão dos dados, tem como foco práticas ativas cujo interesse do estudante, as trocas sociais e a pesquisa são valorizadas no processo de ensino e aprendizagem (PIAGET, 1998). A partir do referencial teórico interacionista de Jean Piaget (1998) e das atuais investigações sobre as tecnologias digitais na educação, propôs-se cursos de extensão para professores que atuam no ensino fundamental. O objetivo da formação foi de capacitar docentes para utilização do AVA Planeta ROODA e promover reflexões a partir de subsídios teóricos sobre práticas pedagógicas, tecnologias digitais e questões socioafetivas na educação.

Esta pesquisa caracteriza-se por ser qualitativa na forma de estudo de casos múltiplos. Os estudos de caso são recomendados para a compreensão de fenômenos sociais complexos e contemporâneos (YIN, 2015). Os casos correspondem aos participantes, os quais se constituem de 13 professores que atuam no ensino fundamental da rede pública e privada do Rio Grande do Sul no Brasil. Os cursos possibilitaram a realização de uma parcela da coleta de dados. As fontes de evidências deste artigo compõem-se de registros de atividades do primeiro curso e de entrevistas semiestruturadas realizadas com 7 participantes, apesar de o convite ter sido enviado a todos. Estas se deram a partir de um roteiro de questões, adaptando-se de acordo com as respostas recebidas e o foco da pesquisa (DELVAL, 2002). Ao ingressar no curso, os participantes foram comunicados sobre a pesquisa, sendo que todos aceitaram mediante assinatura de um termo de consentimento livre e esclarecido.

O curso de extensão teve carga-horária de 40 horas. Na ocasião, foi explorada a segunda versão do Planeta ROODA, o 2.0. As funcionalidades utilizadas foram: Biblioteca (organização de arquivos), Fórum (espaço para debates assíncronos), Planeta Arte (construção de desenhos e compartilhamento), Player (compartilhamento de vídeos) e Webfólio (publicação de postagens e sistema de comentários). As funcionalidades Projetos (postagens coletivas) e Planeta Pergunta (questionários) não estavam em funcionamento durante o curso. De modo geral, foram desenvolvidas atividades como fóruns, análises de objetos de aprendizagem e de vídeos, trocas de opiniões, questionários, análise de situações-problema e, por fim, a elaboração de uma proposta pedagógica para o AVA. A formação proporcionou uma ampla quantidade de evidências, sendo que este artigo apresenta os resultados decorrentes da análise das propostas pedagógicas e de extratos de algumas questões das entrevistas. Ou seja, a discussão e resultados foram desenvolvidos a partir de dados parciais da pesquisa.

\section{Discussão dos dados e resultados}

A discussão dos resultados é realizada a partir das propostas pedagógicas elaboradas pelos professores para o uso do Planeta ROODA 2.0 e das entrevistas. Ao todo, foram analisadas 8 propostas, sendo que duas foram realizadas em dupla. Além dessas, outras 3 foram desconsideradas por não corresponder ao objetivo da atividade. Inicia-se pelas propostas cujas questões orientadoras eram: Qual o público alvo?; Qual a disposição dos estudantes para o trabalho no ambiente virtual?; Qual o foco do projeto ou atividade?; Quais as funcionalidades do Planeta ROODA utilizadas?; Qual a cargahorária?; Como o trabalho deve ser desenvolvido?; Como o docente orienta/intervém no decorrer do trabalho?; Qual a forma de avaliação?

Destaca-se o extrato da proposta pedagógica do participante A, pelo seu potencial para o trabalho de questões sociais e valorização do interesse de estudantes. Prof. A (4 ano): Fórum: [...] escrever sobre o que eles [estudantes] querem aprender 
através do tema: "Um plano para salvar nosso Estado". Responder à pergunta: "como farei para descobrir o que quero pesquisar?" Conversa sobre as ideias propostas e os alunos farão suas pesquisas de acordo com seus interesses, postando no Webfólio.

Ao todo, 2 propostas permitem que os estudantes realizem pesquisas sobre um foco de interesse próprio, ainda que estejam submetidas a uma temática geral. Tal prática proporciona espaço para motivação do sujeito na busca do conhecimento, uma vez que cada um irá escolher o plano para salvar o Estado. Outra proposta cita atividade de pesquisa, porém os grupos escolhem um entre os temas determinados pelo professor. Sob o ponto da teoria interacionista (PIAGET, 1998), o interesse do estudante é um enfoque importante no processo de ensino e aprendizagem. De acordo com Piaget (2014), o interesse está relacionado à força energética voltada a uma finalidade, ou seja, à valorização do objeto ou pessoa. Assim, entende-se que o aluno interessado por um conteúdo e/ou atividade tenderá a investir maior energia nas suas ações.

Ainda quanto às propostas de pesquisa, destaca-se a perspectiva dos métodos ativos, defendida por Piaget (1998), na qual o estudante busca descobrir soluções para os problemas a partir da investigação. $O$ autor acredita que o professor precisa proporcionar múltiplos materiais e diversificar as experiências, tornando o estudante um experimentador ativo (PIAGET, 1998). Logo, a previsão de trabalho com pesquisa é muito satisfatória, no entanto, verifica-se, nas propostas, uma carência de orientações para os estudantes cumprirem o desafio. Esse tipo de atividade é de grande complexidade e esta aumenta ao se utilizar a internet, dada a amplitude e diversidade de informações. Deve-se considerar a existência de conteúdos que não atendam aos objetivos de pesquisas escolares, que não estejam adequados ao nível de compreensão dos estudantes ou, ainda, que sejam impróprios. Uma forma de se realizar esta seleção é construindo critérios junto aos estudantes, o que além de enriquecer a atividade também ensina a criar um método. Um método de pesquisa requer foco definido, critérios claros e referências fidedignas para busca e seleção de materiais, bem como a coerência entre a pergunta inicial e a possível resposta. Nesse contexto, o professor precisa conhecer as concepções prévias dos estudantes, para questioná-los e desequilibrá-los, a fím de promover o interesse pela busca de novas respostas (PIAGET, 1998).

No que concerne à viabilização de práticas ativas, como a autoria de textos, desenhos, imagens, vídeos ou a combinação desses elementos nas propostas, apresentase o seguinte extrato: Prof. L ( $6^{\circ}$ ano): [...] assistir através do "Player" a espetáculos de dança, música e teatro, além de visitar, através de links deixados no "Planeta", Museus e Bibliotecas pelo mundo[...]. Em relação a vídeos, 4 propostas propuseram para os estudantes assistirem vídeos disponibilizados na funcionalidade Player e 1 propõe a produção de vídeo. A maior parte de atividades de autoria é representada por postagens no Fórum e no Webfólio e de desenhos no Planeta Arte.

Quanto às trocas sociais, grande parte das propostas as proporciona através de fóruns e comentários. Por exemplo, Prof. D ( $7^{\mathbf{0}}$ ano): "Assistir aos dois vídeos propostos e participar das discussões no Webfólio, trazendo suas ideias e comentando as dos colegas". Este incentivo ao compartilhamento de materiais entre os estudantes é menos expressivo no total das propostas. Ao realizar uma análise quantitativa, verificou-se entre as 8 propostas consideradas, os seguintes aspectos relativos à socialização através do AVA: 5 incluem o Fórum como a principal funcionalidade para trocas sociais; 3 possuem como foco principal temas sociais (preconceito racial, ideias para salvar o Estado e arte povera); 5 preveem desenho na funcionalidade Planeta Arte e, destas, 1 refere a utilização de comentários dos desenhos entre os estudantes.

Em uma avaliação do curso, questionaram-se os professores quanto à possibilidade de utilizar o Planeta ROODA em práticas pedagógicas, ao interesse em 
novos cursos dentro da temática e ainda às contribuições dos estudos. Em resposta às duas primeiras questões, todos os participantes informaram ter interesse em utilizar o AVA e em realizar outros cursos. De modo geral, os professores apontaram que a formação contribuiu com novos conhecimentos ou auxiliou na retomada de estudos que estavam esquecidos. Quanto à experiência com o ambiente virtual de aprendizagem, os docentes o referem como uma novidade muito interessante para futuros trabalhos com os estudantes. Por outro lado, ao serem entrevistados, após um ano do primeiro curso, questionou-se quanto à utilização de AVA e nenhum deles efetivou uma prática em suas escolas. Alguns argumentos tratavam da falta de laboratório, de internet e de processos burocráticos na escola para inclusão de novas ferramentas. Entre as escolas dos 7 participantes entrevistados, 3 possuem laboratórios de informática desativados e 4 ativos, sendo que destes, 2 não possuem acesso estável à internet. Logo, apenas 2 possuem condições tecnológicas apropriadas na instituição. Porém, um deles cita que o uso para as séries finais do EF é limitado, sendo prioridade para as séries iniciais.

Com essa precária infraestrutura, alguns professores de escolas públicas utilizam, eventualmente, o celular em sala de aula. Dos entrevistados, 4 relataram alguma forma de uso dispositivo, sendo que destas, 3 tratavam e pesquisa na internet. Professor L disse "[...] uso muito o celular com eles". O professor G sugere: "se fosse um ambiente virtual que pudesse se transformar em aplicativo ia ser incrível". Diante deste contexto, verificou-se a demanda de os AVA serem acessíveis através de celulares. Assim, apesar de não ter sido prevista no projeto inicial, definiu-se como prioridade a adequação do Planeta ROODA 3.0 para dispositivos móveis.

\section{Considerações finais}

$\mathrm{O}$ artigo iniciou abordando uma contextualização sobre ambientes virtuais de aprendizagem no ensino fundamental em artigos científicos. O levantamento demonstrou que pesquisas no Brasil com este tema são escassas. Considerando o amplo uso de AVA na educação a distância e o contexto tecnológico atual, entende-se que estudos nesta temática precisam ser mais valorizados e expandidos.

Em relação à pesquisa realizada com professores do ensino fundamental, destaca-se que suas propostas pedagógicas para o Planeta ROODA 2.0 contemplam aspectos interessantes como: compartilhamento de conhecimento a partir de postagens e comentários no Fórum e Webfólio; desenhos no Arte, vídeos no Player e; pesquisas. As produções em grupo e o compartilhamento apareceram de maneira menos expressiva. Acredita-se que a autoria coletiva (ex.: projetos em grupo) e a pesquisa estruturada como um método e a partir do interesse de estudantes poderiam estar mais presentes nas propostas pedagógicas. Um fato que pode ter contribuído para este dado diz respeito à indisponibilidade, durante o curso, de acesso à funcionalidade Projetos (voltada a trabalhos em grupo), por esta encontrar-se na etapa de construção.

Também é importante considerar o esforço dos professores para cumprir o desafio de elaborar propostas pedagógicas para o AVA, sendo que nenhum deles havia desenvolvido práticas em um espaço similar antes do curso. Dominar o ambiente virtual e articular o planejamento a pressupostos teóricos é ainda mais complexo. Assim, para haver a consolidação do uso de tecnologias digitais nas escolas, acredita-se ser necessário investir na formação de professores. Estes precisam atualizar-se e pesquisar sobre tecnologias digitais e suas implicações no processo de ensino e aprendizagem.

Referente às atualizações no Planeta ROODA, a expectativa é de que a sua terceira versão atenda a demandas atuais de usuários do ensino fundamental. Sua interface intuitiva e atrativa, as ferramentas interativas, a página que concentra as 
postagens da turma, lembrando redes sociais, bem como sua estrutura adaptável a dispositivos móveis são novidades interessantes desta versão 3.0.

\section{REFERENCIAS}

BEHAR, P. A.; MACHADO, L. R.; LONGHI, M. T. Domínio Tecnológico: saberes e fazeres na educação a distância. In: Competências em educação a distância. BEHAR, P. A (Org.) Porto Alegre: Penso, 2013.

BRENNAND, E.G.G.; BORGES, L.L. Inteligências múltiplas em ambientes virtuais de aprendizagem: um estudo de objetos de aprendizagem com autoria de crianças.

Ciências \& Cognição. v. 15, n. 3, 2010. Disponível em:

<http://www.cienciasecognicao.org/revista/index.php/cec/article/view/356>. Acesso em: 25 out. 2016.

COSTA, L.A.C.; FRANCO, S.K. Ambientes virtuais de aprendizagem e suas possibilidades construtivistas. Revista Novas Tecnologias na Educação. Porto Alegre, maio, 2005. Disponível em: <http://seer.ufrgs.br/index.php/renote/article/view/13781>. Acesso em: 24 out. 2016.

DELVAL, J. Introdução à Prática do Método Clínico: descobrindo o pensamento das crianças. Porto Alegre: Artmed, 2002.

MACEDO, L. Ensaios pedagógicos: como construir uma escola para todos? Porto Alegre: Artmed, 2005.

PASSERINO, L.M.; GLUZ, J.C.; VICARI, R.M. MEDIATEC - Mediação Tecnológica em Espaços Virtuais para Apoio ao Professor online. Revista Novas Tecnologias na Educação. Porto Alegre, jul. 2007. Disponível em:

<http://seer.ufrgs.br/index.php/renote/article/view/14217>. Acesso em: 24 out. 2016.

PIAGET, J. A tomada de consciência. São Paulo, Melhoramentos, Ed. Universidade de São Paulo, 1977.

. Sobre a Pedagogia: textos inéditos. TRYPHON, A. (Org.). São Paulo: Casa do Psicólogo, 1998.

NILSEN, J. F-Shaped Pattern For Reading Web Content. 17 abr. 2006. Disponível em: <https://www.nngroup.com/articles/f-shaped-pattern-reading-web-content/>. Acesso em: 15 dez. 2016.

RIGO, R.M. Leitura e escrita em ambientes virtuais de aprendizagem. In: Revista Educação Por Escrito. Jan. 2013. Disponível em: <http://link-periodicos-capes-govbr.ez45.periodicos.capes.gov.br/>. Acesso em: 23 out. 2016.

YIN, R. K. Estudo de Caso: Planejamento e Métodos. Porto Alegre: Bookman, 2015.

ZIEGLER, J. de R. et al. O estudo da água através de um ambiente virtual de aprendizagem com alunos do $5^{\circ}$ ano do Ensino Fundamental. Revista Educação Por Escrito, Porto Alegre, v. 5, n. 2, p. 301-314, 2014.

\section{Notas}

${ }^{1}$ O PLANETA ROODA 3.0 está disponível em: <http://www.nuted.ufrgs.br/planeta3>. Acesso em: 30 nov. 2016. 